\title{
A CONTEXTUALIZAÇÃO DO CONHECIMENTO NO ENSINO MÉDIO: TENTATIVAS DE CONTROLE DO OUTRO*
}

\author{
Hugo Heleno Camilo Costa ${ }^{1}$ \\ Alice Casimiro Lopes ${ }^{2}$
}

\begin{abstract}
RESUMO: Em um enfoque discursivo de política de currículo, inspirados nos pensamentos derridiano e laclauniano, focalizamos a ideia de contexto em sua potência desconstrucionista. Defendemos que uma visão estrutural de contexto tende a compreender o conhecimento como estruturante da prática, com vistas ao controle do outro. Assim, possibilidades imprevistas e singulares de ser e decidir são restringidas a uma forma de ser (e decidir), projetada por alguns para todos os outros e suposta como necessária à sociedade. $\mathrm{Na}$ defesa desse argumento, abordamos as Diretrizes Curriculares Nacionais (DCN) desde 1998 e a Base Nacional Comum Curricular (BNCC) como momentos de um texto mais amplo das políticas para o Ensino Médio. Concluímos pela afirmação de outras possibilidades de significação de currículo e contexto que apostam em horizontes democráticos.
\end{abstract}

Palavras-chave: Contexto. Desconstrução. Discurso. Ensino Médio. Política de currículo.

\section{CONTEXTUALIZATION OF KNOWLEDGE IN HIGH SCHOOL: ATTEMPTS TO CONTROL THE OTHER}

ABSTRACT: In a discursive approach to curriculum policy, based on Derrida and Laclau, we focus on the idea of context as a deconstructive power. We argue that a structural view of context tends to place knowledge as the structure of practice, with view to controlling the other. Therefore, unforeseen and unique possibilities of being and deciding are restricted to a way of being (and deciding) projected by some to all others and supposedly necessary to society. In defense of this argument, we have investigated the National Curricular Guidelines

\footnotetext{
*Este trabalho foi realizado com o apoio do Conselho Nacional de Desenvolvimento Científico e Tecnológico (CNPq), por meio de bolsa de pós-doutorado sênior para Alice Casimiro Lopes no Instituto de Estudos da Linguagem da Universidade Estadual de Campinas, e pela Fundação de Amparo à Pesquisa do Estado do Rio de Janeiro, por meio de bolsa de doutorado Nota 10 para Hugo Heleno Camilo Costa.

${ }^{1}$ Universidade Federal do Mato Grosso, Instituto de Ciências Humanas e Sociais, Campus Universitário do Araguaia - Barra do Garças (MT), Brasil. E-mail: hugoguimel@yahoo.com.br ${ }^{2}$ Universidade do Estado do Rio de Janeiro, Programa de Pós-graduação em Educação - Rio de Janeiro (RJ), Brasil. E-mail: alicecasimirolopes@gmail.com DOI: 10.1590/ES0101-73302018184558
} 
since 1998 and the National Curricular Common Base as cut outs of a broader text on policies for High School. We conclude by affirming that there are other possibilities of curriculum and context meaning that aim democratic horizons.

Keywords: Context. Curriculum Policy. Deconstruction. Discourse. High School.

\section{LA CONTEXTUALISATION DU SAVOIR DANS L'ÉCOLE SECONDAIRE: TENTATIVES DE CONTRÔLER L'AUTRE}

RÉSUMÉ: Dans une approche discursive de la politique du curriculum, basée sur Derrida et Laclau, nous concentrons sur l'idée de contexte comme un pouvoir déconstructeur. Nous soutenons qu'une vision structurelle du contexte tend à comprendre la connaissance comme une structuration de la pratique, en vue de contrôler l'autre. Ainsi, les possibilités imprévues et uniques d'être et de décider sont limitées à une manière d'être (et de décider) projetée par certains à tous les autres et supposément nécessaires à la société. En défense de cet argument, nous avons étudié des Directrices Nationales du Curriculum depuis 1998 et la Base Communale Curriculaire Nationale comme moments d'un texte plus large sur les politiques d'École Secondaire. Nous avons conclu qu'il y a d'autres possibilités de sens du curriculum et du contexte qui parient sur les horizons démocratiques.

Mots-clés: Contexte. Déconstruction. Discours. École secondaire. Politique du curriculum..

\section{Situando a problemática}

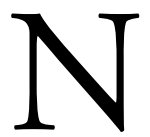

ão é de hoje que o debate curricular valoriza a contextualização do conhecimento. A inserção do conhecimento escolar em um dado contexto, concebido como cotidiano dos estudantes, como prática na qual se aplica um saber (teórico), como espaço de um saber-fazer, ou mesmo como território que pode dar sentido político ao que se aprende, faz parte das disputas de sentido visando significar o que vem a ser currículo. Nessas disputas pela significação, o contexto assume certa positividade, tanto no que concerne a uma propriedade que define suas fronteiras, quanto em relação à expectativa de que a contextualização viabilize melhor o aprendizado, a motivação para o estudo por meio da construção de determinado significado para a vida do estudante, o interesse por um dado saber ou, ainda, o engajamento com a crítica às hierarquias do conhecimento. 
Visando contribuir para esse debate no registro pós-fundacional e pós-estrutural que assumimos, optamos por discutir a noção de contexto proposta por Jacques Derrida e interpretada na política por Ernesto Laclau, procurando realçar sua potência desconstrucionista no âmbito dos estudos curriculares. Temos buscado acompanhar as leituras desses autores, interpretando seus efeitos para o campo do currículo, na medida em que consideramos haver neles um fortalecimento de interpretaçóes mais democráticas, que ampliam as possibilidades políticas do currículo. Acompanhamos Bennington e Derrida (1996, p. 161) quando afirmam que "a desconstrução é o mais radicalmente político dos discursos”. Defendemos tal posição porque consideramos que se trata de um discurso que nem prescreve (pré-escreve) projetos políticos pelos quais se luta nem predefine as identidades inseridas nessa luta, desestabilizando hierarquias de identidades, bem como sedimentaçóes com as quais compreendemos a significação do mundo.

Com foco nas políticas de currículo, argumentamos que o conhecimento escolar que se projeta como contextualizado é estruturado como via de constituiçấo de sujeitos hábeis para decidir conscientemente em contextos previamente concebidos. Nessa prefixação dos contextos, múltiplas possibilidades imprevistas e singulares de ser e decidir são restringidas a uma dada forma de ser (e decidir) que se supóe como necessária a (certa concepção de) sociedade, projetada por alguns para todos os outros.

Ao nos referirmos à política curricular, nela incluímos os sentidos de currículo mobilizados nas práticas acadêmicas e açóes nas escolas, de forma usual denominados, respectivamente, pensamento curricular e contexto da prática. No que concerne à relação com os contextos, defendemos que a política curricular, embora multifacetada, tende a se manter sob a lógica logocêntrica de controle e cálculo sobre o conhecimento e o sujeito (que se espera ser) produzido a partir dele, sobre o devir de distintos contextos de práticas. As práticas, por sua vez, tendem a ser supostas como aquilo que está restrito às ações de professores e estudantes no ambiente escolar. Embora pautados em finalidades sociais distintas, os registros curriculares tendem a comungar do senso de que a escola é um contexto de aplicaçáo de conhecimentos pressupostos e, portanto, passível de controle e arrazoamento. Tal leitura negligencia que toda enunciaçáo sobre as práticas contextuais também é prática contextual, que toda produção de conhecimento, em dado contexto, é um acontecimento - da ordem do inantecipável, como afirma Derrida (2012) - que, revolvendo interpretativamente registros possíveis, busca responder aos desafios que questionam a identidade. Esses registros e suas múltiplas traduções disputam a significação do contexto, da contextualização do conhecimento e da prática, compondo uma formaçáo discursiva na qual textos orientadores das propostas curriculares são produzidos.

Ainda que esse discurso produza significaçóes em toda educação básica, a proposta de contextualização do conhecimento parece ser ainda mais acentuada 
no nível médio de ensino (LOPES, 2002) e, por isso, optamos por destacar este nível. O reconhecido maior vínculo do Ensino Médio com as disciplinas acadêmicas e seu distanciamento de um discurso pedagógico fazem com que a contextualização seja suposta como mais necessária nesse nível de ensino. Desde as Diretrizes Curriculares Nacionais para o Ensino Médio (DCNEM) (BRASIL, 1998), a contextualização é considerada um princípio curricular central, permanecendo, inclusive, na atual proposta de Base Nacional Comum Curricular (BNCC).

Em um enfoque discursivo, interpretamos que todo texto que contém proposta educativa ou acadêmica e que dissemina sentidos sobre currículo é momento de um texto geral da política de currículo. Para os propósitos deste artigo, contudo, focalizamos apenas as DCNEM nos últimos 20 anos, com suas resoluçôes e pareceres (BRASIL, 1998; 2010a; 2010b; 2012), bem como o texto da BNCC $^{1}$ (BRASIL, 2016). Defendemos que tais textos políticos iteram uma perspectiva de estruturação do currículo, via controle do conhecimento e do contexto, visando ao domínio do outro.

Produzidos em diferentes momentos, os referidos documentos foram escolhidos por serem de grande repercussão no debate público e acadêmico e assumirem um caráter de obrigatoriedade e base para a produçáo e proposição de mudanças curriculares nos sistemas educacionais e em diferentes espaços de poder. Para os propósitos de nossa investigação, minimizamos as leituras específicas que podemos fazer de cada texto, justamente por defendermos que, no que concerne à abordagem das relaçóes entre contexto e conhecimento, interessa-nos a recorrência de uma argumentação de controle sobre o contexto.

Como já desenvolvido em outros textos (LOPES, 2015), defendemos que toda tentativa de cálculo sobre o conhecimento, sobre o devir de um fazer curricular, toda tentativa de orientação/controle de práticas de professores e alunos, bem como de qualquer outra identificação envolvida com o campo da educação estão em um movimento de falência ante o potencial generativo de toda significação. A partir desta investigação, questionamos a ideia de que a prática como produção de conhecimento seja lida como circunscrita à determinada instituição ou momento privilegiado - um contexto - , a idealidades e teleologias. Se toda produção de sentido já é uma prática de leitura do mundo, um movimento em favor da hegemonização (LACLAU, 1990) de determinado enfoque ou significação já é também produção de um contexto que se sustenta na tentativa de menção ou referência ao outro que se quer controlar, a quem se quer responder.

Para apresentar o desenvolvimento dessa argumentação, situamos em uma primeira seção a perspectiva derridiana de contexto, mantendo-a associada às ideias de différance, escrita e disseminaçáo, com efeitos importantes no campo do currículo. Focalizamos, na segunda seção, o quanto uma visão estrutural de contexto tende a dar sustentação a enfoques sobre o conhecimento como estruturante da prática, entendendo esta como passível de apreensão e coordenação. 
Nossas conclusóes, por fim, dirigem-se a outras possibilidades de significaçáo das relaçóes entre currículo e contexto que, ao se afastarem das tentativas de fixar a identidade do outro, apostam em finalidades democráticas.

\section{Contexto como construção interpretativa sempre iterada}

Derrida discute a desconstrução de marcadores do logocentrismo e da metafísica ocidental (ARROJO, 1992), buscando atentar para o caráter estabilizador, e de aspiração a verdades absolutas, de distintas formas de pensar o mundo, a vida. Entre seus argumentos, delineia uma perspectiva que chama de "texto em geral" (DERRIDA, 2001). O autor entende que uma textualização do mundo ultrapassa limites de bibliotecas e livros e náo se permite conter ou coordenar por uma verdade ou significado transcendental: é um todo texto geral dinamizado pela diferença, pela traição interpretativa, pela impossibilidade de acesso ao mesmo.

Essa dinamização, para muitos, é suposta como podendo ser contida pela definiçáo das fronteiras do contexto de leitura. Remeter um texto a dado contexto seria uma forma de frear sua significação, de supor um espaço-tempo, um contorno, uma história, uma prática, um ponto de apoio que ofereceria alguma segurança para a interpretação.

Derrida questiona tal pretensão, ponderando que um contexto é uma construção interpretativa, baseada na suposição de um consenso implícito, mas estruturalmente vago, que visa à coordenação do que se deve tratar entre seus limites. Um contexto, afirma ele, visa "prosseguir os diálogos no horizonte de uma inteligibilidade e de uma verdade do sentido" (DERRIDA, 1991, p. 350), de modo a que regras ou acordos gerais possam se instaurar. Desse modo, um contexto para Derrida (1991) nunca é absolutamente delimitável, não podendo ser saturado por qualquer conhecimento ou cálculo anteriores, ser controlado na sua significação. Em qualquer tentativa de sua delimitação, há uma iterabilidade — repetição e citação daquilo a que se supóe referir — levando a que, por mais que se busque ser fiel e contextualizar a citação, jamais se consiga manter intacta a significação do que se pretende reproduzir. Derrida (1991) pontua que a iterabilidade, ao mesmo tempo em que autoriza, corrompendo regras e códigos que constitui, difunde a alteração na repetição, a disseminação do sentido na citação.

Propostas curriculares, por exemplo, citam teorias e conceitos, outras propostas e práticas, articulam perspectivas que foram produzidas sem necessariamente pressupor uma relação entre elas: é afirmado que vêm de contextos diversos. Muitas vezes, é na prática discursiva de produção de um documento curricular que tais textos são (su)postos em relaçáo. Tal capacidade de uma marca ser citada e/ou duplicada, enfim, a iterabilidade de uma marca, um termo, uma ideia, não é um acidente, mas aquilo do que uma marca náo pode prescindir para ter sua operação 
considerada normal (DERRIDA, 1991). A partir desta asserção, Derrida (1991, p. 362) questiona: “O que é que poderia ser uma marca que não se pudesse citar?".

Contextos são, assim, fraturados em sua estrutura. A repetiçáo aditiva da différance leva à falência os intentos de menção ao referencial, ao que se supóe como origem ou espaço comum do próprio contexto, dilacera sentidos articulados sob um mesmo nome/contexto/significante. Dessa forma, ao mencionar o contexto, já não estamos nele ou o acessando, mas estamos adulterando a ideia daquilo que mencionamos, traindo, engendrando outros contextos, vivendo noutra contextualização.

Derrida (1991) não desconsidera que a delimitação de um contexto possa vir a ser necessária. Chama atenção, entretanto, que qualquer delimitação, por mais necessária que seja, por mais obrigatória que aparente ser, sofre interdição pela différance, enfatizando a flutuação e a precariedade que motivam todo signo.

Essa indeterminação do contexto de produção de algo também se impõe para a intenção de significaçáo e para o enunciado. Derrida (1991) considera que, para que um contexto fosse saturável, determinável, a intenção precisaria atuar como sua diretriz dominante, o que a colocaria diante da necessidade de ser (ou ter seu conteúdo) absolutamente presente e transparente a si mesmo e aos outros. Em contraposição a essa ideia, ele defende que a "ausência essencial da intenção na atualidade do enunciado, esta inconsciência estrutural” (DERRIDA, 1991, p. 369) impossibilita a saturação, ou apreensão totalizada, de um contexto.

Para Derrida (1991), a iteração, no sentido mesmo da alteridade como irrupção, que altera e faz com que algo novo aconteça, contamina a intenção e leva a que todo ato performático/de fala/escrita/tradução expresse algo diverso do que se pretendia dizer. A traição, tal como concebida por Derrida (1991), encerrada na/pela escrita, não quer negligenciar a existência da intenção ou da consciência. A intenção, segundo o autor, pode ter seu lugar, mas a partir dele já não é capaz de coordenar a significação. Nessa perspectiva, destaca-se o caráter inconsciente, singular e intenso da tradução como iteração, tendo em vista seu dinamismo produtivo e, simultaneamente, sua capacidade de frear aspiraçóes homogeneizantes de (con)textualização.

Entender a iteração/tradução como um meio de articulação e traição irresistível e permanente é pontuar que contextos são (in)fundados fragilmente, porque constituídos por uma fé (DERRIDA, 2007) de se estar tratando da mesma coisa em relação a dado significante, na ligação com o outro. Ao fazê-lo, dinamiza-se a ruptura com todo contexto determinado, gerando infinitamente outros contextos que, por sua vez, também são absolutamente não saturáveis.

Se não há conhecimento ou consciência transcendental, controle absoluto do sentido e tampouco há limites e propriedades do contexto (DERRIDA, 1991), somente há um movimento de disseminação generativo de novos sentidos. A disseminaçáo, inerente a todo envolvimento com a/na linguagem, proporciona 
tão somente a produção de efeitos semânticos infinitos e o bloqueio da reconduçấo a uma origem simples. Ela é o "suplemento e a turbulência de uma certa falta" (DERRIDA, 2001, p. 52) que fratura os limites do texto, da significação do mundo, de um querer-dizer.

Com isso, não defendemos que a ruptura contextual, por meio da disseminação/différance, seja uma expressão destoante. Salientamos, todavia, que, julgando tratar do mesmo, do próprio, já se está suplementando, produzindo outros sentidos na relação com aquilo que se julga tratar. É reconhecer que se joga com a semelhança, com o parentesco, com a simulação, com o acontecimento, a ficção de uma presença que é pura ausência (DERRIDA, 2001).

Toda enunciação de um contexto - escolar, acadêmico, científico, local, global - é, assim, uma ficção de limites, ao mesmo tempo em que é uma decisáo indecidível do que se supóe como contextual, um resultado de atos de poder envolvidos em uma decisão. Como já discutido em Lopes (2015), o contexto não é obrigatoriamente local, restrito, próximo, localizado na vida cotidiana ou na escola. O conhecimento (escolar) não emerge da escola: ele só tem significado em um contexto discursivo, descentrado e constantemente deslocado (LACLAU, 1990), submetido às lutas políticas que possibilitam sua enunciação. E, como toda enunciação, sempre remete à tradução/iteração.

Com esta leitura, passamos a focalizar marcadores da política curricular que tendem a projetar contextos como passíveis de serem acessados, controlados, analisados, por serem entendidos como limitados e precisos em sua significação, verdadeiros e transparentes, submetidos a uma intervençáo calculada.

\section{O contexto do conhecimento na política curricular}

Na política de currículo para o Ensino Médio, as transformações científicas, comportamentais e sociais contemporâneas são projetadas como forma de respaldar uma visão de mundo suposta como dada, como algo com o qual temos de lidar de forma transparente e direta. Tal perspectiva é afirmada como latente, devendo ser apropriada por meio de um conhecimento integrado, via interdisciplinaridade/temas integradores, capaz de realizar a inclusáo social, a preparaçáo para o mundo do trabalho, a formação ética, flexível, autônoma e crítica do sujeito, para que possa atuar e adaptar-se aos mais distintos contextos sociais.

O conhecimento, projetado no centro do que vem a ser a função da educação/currículo, faculta ao contexto a oportunidade para a formação de competências e habilidades capazes de produzir subjetividades incluídas socialmente, produtoras de conhecimento e cidadâs (BRASIL, 1998, p. 16). É também nessa perspectiva que a organização curricular é pensada como meio de assegurar o 
entendimento de currículo como experiências escolares que se desdobram em torno do conhecimento, permeadas pelas relaçóes sociais, articulando vivências e saberes dos estudantes com os conhecimentos historicamente acumulados e contribuindo para construir as identidades dos educandos (BRASIL, 2010b, p. 5).

Tal leitura possibilita a conjectura de que a cidadania, a subjetividade e as formas de conceber o mundo estão condicionadas a um conhecimento (ainda) não obtido pelos estudantes, mas virtualmente proposto de forma centralizada pelos textos da política: "os conhecimentos essenciais a que todos os estudantes brasileiros têm o direito de acesso e de apropriação durante sua trajetória na Educação Básica” (BRASIL, 2016, p. 30). Ao focalizar a "segurança" no entendimento do currículo como organizador da proposta, o conhecimento é dado como para além das relaçóes sociais, alheio ou estranho a elas, algo a que se tem o direito de acesso, náo de produção. A dimensão experiencial (saberes e vivências dos estudantes) da escola é considerada como o que deve cercar, ou estar ao redor, do que consiste no fim do fazer curricular: a formação de identidades a partir dos conhecimentos acumulados.

O conhecimento é pensado como aquilo que tende a valorizar o contexto escolar (por não ser constituinte dele), sendo projetado como propriedade fundante da aquisição ou conquista de uma cidadania e de um direito, de uma possibilidade de ser sujeito no que é lido como sociedade, para o que é dado por mundo. Na mesma afirmação possível, o contexto da escola é um lócus estável, cuja produçáo de sentidos é limitada perante os conhecimentos supostos como importantes à cidadania.

Argumentamos que a consideração marginal do que vem a ser o contexto que se visa alcançar, por meio da noção de respeito às diferenças (regionais e locais), saberes e experiências, mantém a busca pelo controle, mas também supóe que sem a negociação com aquilo que dinamiza o contexto não se pode continuar. A busca pelo controle do outro - do que se quer controlar no e do contexto não pode se dar sem a exposição disso que diz "eu" na política (a subjetivação precipitada nesses momentos da política que constituem os documentos oficiais). A exposição (resposta) oportuniza a leitura de que há um não saber em relação ao outro contextual, do qual se depende para avançar.

A esse respeito, como também é proposto no Parecer no 07/2010 (BRASIL, 2010a, p. 5) e nas DCNEM (BRASIL, 2012, p. 6), interessa destacar:, interessa destacar:

A organização do percurso formativo, aberto e contextualizado, deve ser construída em funçáo das peculiaridades do meio e das características, interesses e necessidades dos estudantes, incluindo não só os componentes curriculares centrais obrigatórios, previstos na legislação e nas normas educacionais, mas outros, também, de modo flexível e variável, conforme cada projeto escolar. 
XII - formas diversificadas podem ser organizadas, desde que garantida a simultaneidade entre as dimensóes do trabalho, da ciência, da tecnologia e da cultura, e definidas pelo projeto político-pedagógico, atendendo necessidades, anseios e aspirações dos sujeitos e a realidade da escola e do seu meio (BRASIL, 2012, p. 6, grifo nosso).

A consideração da abertura e da contextualização é remetida à peculiaridade das características de um contexto escolar desconhecido e incontrolável, uma vez que é potencialmente mais dinâmico do que o que está circunscrito ao normativo. Só se acena para esse contexto escolar ressalvando a função dos componentes curriculares centrais e obrigatórios, autorizados pela legislação que normatiza o currículo.

Entre as possibilidades interpretativas, a revisitação do argumento de respeito ao projeto escolar, "desde que" incorporada a normatizaçáo que vem ao contexto para fazê-lo previsível (calculado, controlado, conhecido), assinala o movimento pelo controle de uma alteridade que é furtiva a toda forma de controle. Isso porque, na perspectiva com a qual operamos, a alteridade contextual não é uma verdade transparente e ao mesmo tempo é imprevisível. Tal imprevisibilidade, por sua vez, parece fazer a política requerer ainda mais empenho controlador na busca por mais proximidade em relação ao outro e, simultaneamente, por resguardar aquilo que se julga como propriedade constitutiva de si, de se manter (ou proteger) na relação com o outro.

Pensamos tal referência à propriedade como também significando o conhecimento a ser transmitido no que se lê por contexto (da escola, experiência, vida). Há uma ideia de transmissão que depende da construção de significados fixos do que vem a ser isso mesmo (alter) que se quer controlar, mas se desconhece em presença. Argumentamos sobre as dinâmicas que, perfazendo um texto mais amplo de política curricular, disseminam leituras de valorização do contexto, tendo tal contexto como objeto de conhecimento. Desse modo, busca-se circunscrever ou significar de uma vez por todas o que é, quem possui, como se produz e quais são as finalidades do que se pode chamar por conhecimento.

$\mathrm{O}$ trecho a seguir reforça essa argumentação, ao ponderar sobre:

IV - compreensão da matriz curricular entendida como propulsora de movimento, dinamismo curricular e educacional, de tal modo que os diferentes campos do conhecimento possam se coadunar com o conjunto de atividades educativas;

V - organização da matriz curricular entendida como alternativa operacional que embase a gestáo do currículo escolar e represente subsídio para a gestão da escola (na organização do tempo e do espaço curricular, distribuição e controle do tempo dos trabalhos docentes), passo para uma gestáo centrada na abordagem interdisciplinar, organizada por eixos temáticos, mediante interlocução entre os diferentes campos do conhecimento; 
VI - entendimento de que eixos temáticos são uma forma de organizar o trabalho pedagógico, limitando a dispersão do conhecimento, fornecendo o cenário no qual se constroem objetos de estudo, propiciando a concretizaçáo da proposta pedagógica centrada na visão interdisciplinar, superando o isolamento das pessoas e a compartimentalização de conteúdos rígidos (BRASIL, 2010a, p. 65).

Esses itens, parecendo visar à segurança da proposta, podem ser pensados como apoiando a perspectiva de um conhecimento central da matriz curricular, a ser mobilizada a partir da integraçáo das disciplinas, capaz de manter envolvimento com as atividades educativas. Passa pela ideia de que, com essa reorganização do conhecimento, a função operacional da gestão do trabalho pedagógico terá êxito. A reorganização curricular via interdisciplinaridade também introduziria melhorias nas relaçóes pessoais para a construção de um conhecimento interessante à vida dos sujeitos.

Todos os textos investigados partem dos princípios da interdisciplinaridade e contextualização como forma de assegurar que não só o conhecimento científico, relacionado às disciplinas escolares, é fundamental para a produção de sujeitos competentes, mas também a produção de sentidos em e para contextos privilegiados controla as formas de operação de tais conhecimentos com os sentidos/significados adequados, supostos como ideais para a sociedade atual.

Tal perspectiva se volta à ideia de que, para além dos significados a serem respeitados na relação com o contexto, importa sua complexificação com uma forma de conhecer suposta como não produzida ou como impossível nesse mesmo contexto sem que haja uma intervenção reformista. Não só o contexto é pensado como possuidor de significados fixos, como esses mesmos significados são considerados insuficientes para a consecução do que se define por objetivo curricular. A condiçáo do conhecimento (do outro) do contexto, por não ser considerada potente para fins de integração de conhecimentos e relaçóes, precisa ser administrada visando ao foco na produção de formas de saber pensadas como ausentes desse mesmo contexto. Exemplarmente, as dispersóes do conhecimento, das relaçóes sociais e das formas de operar contextuais, importantes para o que se define a priori do contexto, são defendidas como podendo ser combatidas por um conhecimento também não definido pela proposta. Assim, ao mesmo tempo em que é secundarizada uma possível verdade operante no contexto escolar, a decisão pela reforma focaliza a responsabilização de outro contextual, operante e atuante no contexto. Esse outro é quem deve entrelaçar todo um conjunto de elementos afirmados como dados, e potentes, para a aquisição do que é negativamente ponderado como faltoso.

Pensamos que os argumentos em questão enfatizam a ideia de controle, pois não basta não saber o que o outro sabe (pois não se sabe). É preciso dizer como se deve pensar para ser sujeito cidadão, a partir de um conjunto de atitudes a serem construídas por um conhecimento integrado às verdades contextuais que extrapolam o contexto da afirmação da própria reforma. Não há certeza ou precisão 
sobre a capacidade dinâmica de determinada forma de conhecer, mas sustenta-se ser necessária a negociação com os saberes outros circulantes na escola, para que o conhecimento privilegiado, afirmado como central para o contexto da escola, possa surtir determinados efeitos, a partir de sua integração e na relação com o que é afirmado como outro. Uma vez que o outro é desconhecido em suas propriedades, importa destacar o investimento na qualificação da proposta de reforma por meio da definição do que falta para e no outro do contexto. Com isso, também se define esse contexto (o da própria reforma) como referencial para aquilo que escapa.

Corroborando esta perspectiva, o trecho a seguir focaliza os princípios e as finalidades orientadores do Ensino Médio, nos quais é definida a importância de consolidação de determinado conhecimento com vistas à sua contextualização (no que se busca afirmar como contexto possível para o sujeito).

I - a consolidaçáo e o aprofundamento dos conhecimentos adquiridos no Ensino Fundamental, possibilitando o prosseguimento de estudos;

II - a preparaçáo básica para a cidadania e o trabalho, tomado este como princípio educativo, para continuar aprendendo, de modo a ser capaz de enfrentar novas condiçôes de ocupação e aperfeiçoamento posteriores;

III - o desenvolvimento do educando como pessoa humana, incluindo a formaçáo ética e estética, o desenvolvimento da autonomia intelectual e do pensamento crítico;

IV - a compreensão dos fundamentos científicos e tecnológicos presentes na sociedade contemporânea, relacionando a teoria com a prática.

$\$ 1^{\circ} \mathrm{O}$ Ensino Médio deve ter uma base unitária sobre a qual podem se assentar possibilidades diversas como preparaçáo geral para o trabalho ou, facultativamente, para profissōes técnicas; na ciência e na tecnologia, como iniciação científica e tecnológica; na cultura, como ampliação da formaçáo cultural.

$\$ 2^{\circ}$ A definiçãa e a gestáo do currículo inscrevem-se em uma lógica que se dirige aos jovens, considerando suas singularidades, que se situam em um tempo determinado (BRASIL, 2010b, p. 8).

Os contextos da escola, do trabalho e da continuidade na vida estáo inscritos como promessas a serem concretizadas ou relacionadas à aquisição do conhecimento, ao mesmo tempo em que as singularidades da juventude, da prática a ser relacionada com o que se tem por teoria, e de uma intelectualidade e criticidade são projetadas como objetivos que, não sendo passíveis de controle, devem ser desenvolvidos ou resolvidos para que o sujeito saiba lidar com novas 
situaçóes. Essas situaçóes são lidas como restritas às atividades ocupacionais e/ou de qualificação laboral, conectando-as ao sucesso da formação da pessoa humana.

Vale destacar que o trabalho é apresentado comumente como "transformação da natureza e produção da existência" (BRASIL, 2016, p. 490), "entrelaçado à ciência e tecnologia" (BRASIL, 2016, p. 492), sendo assumido como contexto prioritário para o currículo. Mas, simultaneamente, vincula-se à capacidade de prover o próprio sustento (BRASIL, 2016, p. 490), ação humana transformadora e emprego. Estes são contextos nos quais o conhecimento deve se desdobrar em competências com potencial preparatório para a atuação do sujeito em diferentes situações no "mundo das ocupaçôes" (BRASIL, 1998). Com base na meta de inserção no "mundo do trabalho", ainda que apartada da formação para uma habilitação profissional (BRASIL, 2016, p. 497), é defendido que o conhecimento não pode ser fragmentado, como em um modelo disciplinar tradicional, mas deve ser interdisciplinar e contextualizado (BRASIL, 1998, p. 37), apropriandose dos conhecimentos das diferentes disciplinas para a formação de sujeitos competentes para atuar em distintos contextos previstos. Trata-se de uma ideia de conhecimento contextualizado, que nega uma possível construçáo contextual, nos imprevistos momentos de produção curricular. Isso possibilita a leitura de que o conhecimento defendido é produzido anteriormente ao contexto e está voltado para uma "função contextual" hábil em tornar a escola "capaz" de produzir sujeitos "capazes" de (vir a) ser.

Com foco na complementação do texto das Diretrizes e, nesse movimento, envolvido na sua reafirmação como já sendo uma base nacional comum, o Parecer do CNE/CEB no 07/2010 (BRASIL, 2010a) é definido sob a justificativa de que as DCNEM de 1998, assim como os parâmetros curriculares nacionais para o Ensino Médio não lograram êxito em razão de falta de diálogo com o cotidiano escolar. Como solução para a ineficiência das propostas, o Parecer que institui as diretrizes coloca como desafio "garantir, contextualizadamente, o direito humano universal e social inalienável à educaçáo" (BRASIL, 2010a, p. 11). A partir dessa motivação, é afirmada a necessidade de a escola se reinventar de modo a "gerar sujeitos inventivos, participativos, preparados para diversificadas inserçóes sociais, políticas culturais, laborais" (BRASIL, 2010a, p. 11).

O currículo é tomado como produção social contínua, atravessada por diferentes identificaçóes e mediaçóes de contextos definidos como possuidores de determinados significados (a ciência, os órgãos de gestão, a escola, a comunidade). Também são destacados processos de interpretação, bem como são reiteradas as fronteiras entre o formal e o não formal na produção curricular. Na defesa do formal, é apresentado o que se espera garantir na educação escolar:

Liberdade de aprender, ensinar, pesquisar e divulgar a cultura, o pensamento, a arte e o conhecimento científico, além do pluralismo de ideias e de concepçóes pedagógicas, assim como a valorizaçáo da experiência extraescolar, e a vinculaçáo entre a educação escolar, o trabalho e as práticas sociais (BRASIL, 2010a, p. 19). 
Essa liberdade inscreve a escola como contexto cujo fim é operar com dinâmicas de aprendizagem e ensino de uma cultura anterior, além de colocar a experiência extraescolar, o trabalho e as práticas sociais como responsabilidades dessa mesma escola. Entre tais práticas sociais, é pertinente destacar a afirmação de que a atualidade vivida pela sociedade, atravessada por múltiplas inovaçóes científicas e tecnológicas que adentram a escola por intermédio dos alunos, impóe a valorização da ciência e da tecnologia ao longo de toda a educação básica (BRASIL, 2010a, p. 21). Com esta leitura, o exercício da cidadania é condicionado também ao domínio do conhecimento científico.

Tanto o conhecimento quanto a realidade são tomados como nomes possuidores de significados últimos e transparentes ao que se pondera por contexto. Nessa interpretaçáo, a formaçáo do sujeito depende obrigatoriamente da aquisiçáo do conhecimento afirmado como empoderador de determinada visão emancipatória - enunciada, por sua vez, como definida pelos conhecimentos científicos introduzidos pelas disciplinas e que precisam ser articulados em projetos (de distintas flexôes disciplinares e temas). Nesse sentido, constituindo um fundamento das formas de conhecer, o nível médio é pensado como devendo "proporcionar ao estudante uma formação com base unitária, no sentido de um método de pensar e compreender as determinaçóes da vida social e produtiva; que articule trabalho, ciência, tecnologia e cultura na perspectiva da emancipação humana" (BRASIL, 2010a, p. 35).

A preocupação com a reorganização curricular na escola se desdobra em propostas integradas de currículo, nas quais o conhecimento ganhará novos significados na formação de sujeitos (BRASIL, 2010a). É defendida a autonomia da escola na elaboração de experiências contextuais que oportunizem a integraçáo dos conhecimentos disciplinares rumo a um conhecimento capaz de resolver problemas da realidade.

A parte diversificada enriquece e complementa a base nacional comum, prevendo o estudo das características regionais e locais da sociedade, da cultura, da economia e da comunidade escolar. [...] E organizada em temas gerais, em forma de áreas do conhecimento, disciplinas, eixos temáticos, selecionados pelos sistemas educativos e pela unidade escolar, colegiadamente, para serem desenvolvidos de forma transversal. A base nacional comum e a parte diversificada não podem se constituir em dois blocos distintos, com disciplinas específicas para cada uma dessas partes (BRASIL, 2010a, p. 27).

Uma lógica interessante tende a ser a compreensão do contexto como sendo passível de implementação de propostas e leituras de mundo, cuja atividade e autonomia estariam restritas à apropriação local/diversa de formas de conhecer comuns. O contexto (local, regional, na escola, na comunidade) estaria encarregado da contrapartida de uma proposta emancipatória de conhecimento a partir da definição de temas que, como exemplos das preocupaçóes mais amplas do que é tomado como básico e comum, convergiriam para o/no conhecimento científico, lido como básico e comum. Tal perspectiva é consolidada no trecho em que se afirma: 
Entende-se por base nacional comum, na Educaçáo Básica, os conhecimentos, saberes e valores produzidos culturalmente, expressos nas políticas públicas e que são gerados nas instituiçóes produtoras do conhecimento científico e tecnológico; no mundo do trabalho; no desenvolvimento das linguagens; nas atividades desportivas e corporais; na produção artística; nas formas diversas de exercício da cidadania; nos movimentos sociais, definidos no texto dessa Lei, artigos 26 e 33, que assim se traduzem:

I - na Língua Portuguesa;

II - na Matemática;

III - no conhecimento do mundo físico, natural, da realidade social e política, especialmente do Brasil, incluindo-se o estudo da História e Cultura Afro-Brasileira e Indígena,

IV - na Arte em suas diferentes formas de expressão, incluindo-se a música;

V - na Educação Física;

VI - no Ensino Religioso.

Tais componentes curriculares são organizados pelos sistemas educativos, em forma de áreas de conhecimento, disciplinas, eixos temáticos, preservando-se a especificidade dos diferentes campos do conhecimento, por meio dos quais se desenvolvem as habilidades indispensáveis ao exercício da cidadania, em ritmo compatível com as etapas do desenvolvimento integral do cidadão (BRASIL, 2010a, p. 26-27).

Igualmente, o papel da escola é reiterado em suas contribuiçóes para a proposta curricular defendida, cabendo à escola a construção de um projeto político-pedagógico e curricular que leve à produção de conhecimento favorável à interação de "temas significativos que se relacionem com problemas e fatos culturais relevantes da realidade em que a escola se inscreve" (BRASIL, 2010a, p. 44).

Em ressonância com tais determinações, e reiterando a Resolução no 04/2010, o Parecer define o Ensino Médio como devendo assegurar a permanência do jovem na escola, por meio da proposição de "currículos flexíveis, com diferentes alternativas, para que os jovens tenham a oportunidade de escolher o percurso formativo que mais atenda aos seus interesses" (BRASIL, 2010a, p. 35). Ao mesmo tempo, introduz uma gradação na definição deste nível de ensino, ao focalizar seu caráter de terminalidade na Educação Básica e preparação para o trabalho e a cidadania.

Ainda nesse movimento de definição do contexto do Ensino Médio no âmbito da Educação Básica, visando reduzir o que é tomado como distanciamento 
entre a escola e as práticas sociais, determina-se a importância de uma base unitária de formação na qual se inscrevam as possibilidades para o sujeito cidadão a ser formado, que consistem no

trabalho, como preparação geral ou, facultativamente, para profissões técnicas; na ciência e na tecnologia, como iniciação científica e tecnológica; nas artes e na cultura, como ampliação da formação cultural. Assim, o currículo do Ensino Médio deve organizar-se de modo a assegurar a integraçáo entre os seus sujeitos, o trabalho, a ciência, a tecnologia e a cultura, tendo o trabalho como princípio educativo, processualmente conduzido (BRASIL, 2010a, p. 35).

Com estes argumentos, interessa assinalar a decisão por um projeto de contexto escolar, bem como seu fim de formação para a cidadania, sua afirmação como preparação para o mundo do trabalho, este sim capaz de definir o que é ser cidadão, ser incluído e possuidor de direito.

Nas DCNEM de 2012, ainda que mobilizadas pela missão de atender às necessidades não contempladas pelas DCNEM de 1998, é defendida a maior qualificação de sujeitos para o desenvolvimento industrial do país. A formação do sujeito ideal para o contexto privilegiado do trabalho e das mudanças contínuas deste trabalho é congregada nas missóes de oportunizar a inclusão social e a cidadania. Tal proposta possibilita a leitura de que produzir sujeitos para o acertado mundo do trabalho é, necessariamente, formar cidadãos/trabalhadores autônomos, críticos e reflexivos, que saibam lidar com os desafios vindouros de mundo assumido como dinâmico. E este mundo parece se evidenciar táo mais dinâmico quanto mais a escola — como se fosse externa ao mundo - é lida como contexto da falta de dinamismo.

Para dar conta de constituir condiçóes ideais, a escola passa a ser lida como contexto primordial de difusão "sistemática dos conhecimentos científicos construídos pela humanidade" (BRASIL, 2012, p. 150). Apesar disso, ao longo do texto é defendida a necessidade de que o sucesso da educação, da produção do conhecimento, diga respeito à relação que a escola precisa estabelecer com o projeto de vida dos estudantes (BRASIL, 2012, p. 155).

Uma visão de conhecimento científico integrado, nesse caso, é tomada como pressuposto fundante das formas de conhecer circulantes no currículo. A aplicação contextual desse conhecimento asseguraria o fechamento do hiato entre a teoria e a prática, produzindo sujeitos conhecedores daquilo que é desejado para ser aplicado no que é afirmado como o contexto (sociedade, trabalho).

A apropriação de conhecimentos científicos se efetiva [...] com contextualizaçáo que relacione os conhecimentos com a vida, em oposição a metodologias pouco ou nada ativas e sem significado para os estudantes. Estas metodologias estabelecem relação expositiva e transmissivista que náo coloca os estudantes em situação de vida real, de fazer, de elaborar (BRASIL, 2012, p. 167). 
Ao longo dos textos das DCNEM (BRASIL, 1998; 2010a; 2010b; 2012), o conhecimento científico interdisciplinarizado via contextualização é sinalizado como capaz de constituir subjetividades para operar contextualmente. O conhecimento é apreendido como limitado a contextos considerados garantidos, ou mesmo passíveis de serem saturados em termos de possibilidades de experiência do sujeito em questão, possibilidades de acontecimento. Tais abordagens restringem assim o conhecimento suposto como base das formas de aplicação em contextos desejáveis, ideais para o sujeito forjado na idealidade de um currículo calculado (de cima para baixo ou de baixo para cima; interdisciplinar, mas contextualizado adequadamente, em um contexto determinado).

A busca pela reiteração de formas de controle contextuais, a afirmaçáo de uma propriedade comum e desejável à transmissão ou reprise na e para a escola seguem dinamizada no documento da BNCC. Na proposta da BNCC, contudo, é registrada de forma mais contundente a ideia de educação como direito a ser apropriado pelo sujeito. Tais direitos gerais para a Educação Básica são remarcados na versão 2 e incorporados como competências gerais da BNCC em sua terceira e última versão. $\mathrm{Na}$ versão 2 , os direitos são definidos como a serem apropriados na escola, como aquilo de que se necessita para ser sujeito e cidadão, o que a escola não pode se furtar a oferecer e garantir ao sujeito em formação.

$\mathrm{Na}$ versão final, as competências assumem a conformação de objetivos educacionais, embora mantenham a defesa do conhecimento como conteúdo a ser apreendido na escola para a construçáo de um sujeito cidadão, capaz de performar o que é orientado como operação esperada nos contextos previstos para sua vida.

Assim como destacado nos documentos que perfazem as DCN (BRASIL, 1998; 2010a; 2010b, 2012), na BNCC é defendida a ideia de que o conhecimento predefinido precisa ser organizado, no contexto da escola, de maneira plausível aos fins do nível médio, com vistas à superação da fragmentação dos conhecimentos. Essa organização do ensino é considerada como o currículo, negando a identificação da BNCC como currículo, ainda que a todo tempo esta base busque criar uma ordem curricular. Nesse sentido, a ideia de articulação de conhecimentos disciplinares, em uma reorganização de seu funcionamento na escola, busca aumentar a aderência da proposta à experiência curricular afirmada para o contexto escolar e, portanto, ao cumprimento do direito à educaçáo por meio da formaçáo das competências. O projeto de um sujeito cidadáo, de consciência plena, criativo, sociável, para o mundo do trabalho, precisa ser realizado em uma matriz curricular afeita à integração dos conhecimentos disciplinares, de modo que em tal perspectiva seja possível sua realização na escola, e desta para a vida: uma contextualização capaz de preparar o sujeito para um todo-saber-fazer nos mais diferentes contextos com que vier a lidar.

A juventude que conclui o Ensino Médio deve ser capaz de questionar, analisar e posicionar-se criticamente no mundo; comunicarse e intervir em diferentes contextos, usando as várias linguagens 
(oral, escrita, científica, digitais, artísticas e corporais); solucionar problemas de forma criativa e inovadora; interagir com o outro e suas diferenças; reconhecer, expressar e gerir suas emoçóes; liderar, empreender e aprender continuamente (BRASIL, 2016, p. 491).

Para a construçáo de tais capacidades, o texto da BNCC condiciona o respeito a dois "caminhos de integração": o primeiro, concernente às "contribuiçôes de vários componentes curriculares para a efetivação da formação integral" (BRASIL, 2016, p. 494) e o segundo, associado à presença dos objetivos de aprendizagem. Estes caminhos são defendidos como devendo ser integrados, de maneira que a interdisciplinaridade dos componentes curriculares possa ser viabilizada pelos temas integradores, lidos como fundamentais aos contextos vivenciados pelos sujeitos no mundo atual (BRASIL, 2016).

Diante dessa proposiçáo, é reafirmada para a escola a responsabilidade de que o jovem faça "correlaçáo e sínteses que lhe permitam dar sentido e unidade ao mundo em que vive" (BRASIL, 2016, p. 495). Da mesma forma, no âmbito de um controle contextual sobre o que deve ser priorizado na escola e na virtual experiência do sujeito no mundo, é apontada a abrangência de tais significados por meio das áreas de conhecimento, preenchidas pelos componentes curriculares. Com esta noção, interessa destacar a reduçáo de uma incontrolável significação última do mundo às formas de ler o mundo contidas nos componentes definidos como BNCC (CUNHA; LOPES, 2017), restritos ao que é delimitado pelo documento na relação com os campos disciplinares.

\section{Considerações finais}

Na política de currículo, como procuramos argumentar até aqui, o contexto tende a ser visto como aquilo objetivado a que se pode referir e inferir em sua plenitude, sua estrutura e funcionamento; um espaço-tempo aberto ao olhar pleno de um analista, interventor. Desse modo, é projetada uma propriedade do conhecimento a ser transmitido pela escola. Por sua vez, é legada à escola a função de produzir aquilo mesmo que não se encontra na proposta, porque tudo é projetado para ser desenvolvido no e pelo contexto escolar. Esta propriedade, mobilizada pelos conhecimentos disciplinares, é pensada como devendo ser encaminhada para uma visão integrada de conhecimento que só pode ser constituída pela escola, em sua contrapartida contextual. É responsabilidade da escola, por meio da interdisciplinaridade dos conhecimentos com vistas à formação de competências, o alcance de objetivos de aprendizagem e a garantia de direitos.

Supor um dado conhecimento como tendo onipotência funcional para todo contexto (da escola, do trabalho, da família, da sociedade, qualquer enunciação contextual) assinala uma tentativa de cálculo sobre as formas de conhecer (n) 
o mundo, de lidar com o desconhecido, de aplacar o questionamento ignorado de uma alteridade "toda outra" (Derrida, 2006) que impóe, continuamente, a necessidade de revolvermos nossas formas de conhecimento, sejam elas quais forem, para responder aquilo que se supóe, em uma linguagem opaca, como a inquisição a que não se pode escapar. Não só o contexto não é algo calculável, como o conhecimento possível e passível de operação contextual não é uma propriedade carregada por um sujeito de razão/consciência transcendental, ou que possa ser causado por uma propriedade de conhecimento.

Uma vez que o contexto não pode ser saturado por razão alguma, não pode ser recuperado, o conhecimento pode ser considerado como aquilo que resulta da decisão de resposta de uma subjetivação (DERRIDA, 2006). Apesar de toda tentativa de controle, o que é reunido e tomado como conhecimento plausível reside na decisão em resposta, ocasião em que supomos ser precipitada a subjetivação (LACLAU, 1998), a virtualidade do sujeito. Se, de alguma forma, apostamos em possibilidades democráticas, no sentido nunca alcançado plenamente, proposto por Laclau (2001) e discutido por Lopes (2012) para o campo do currículo, apostar na fixação e no cálculo dos possíveis contextos da vida apenas restringe tais possibilidades.

De forma diferente, apostamos na potência de se operar em uma perspectiva de currículo como texto (LOPES \& MACEDO, 2011), enfatizando o caráter textual do mundo (DERRIDA, 1991; 2001). Esta perspectiva nos leva a supor que toda significação do currículo é tão somente uma forma de envolvimento, um efeito de poder; toda prática é prática de significação, de produção de sentidos, de conhecimento, de hegemonização (LACLAU, 1990) de determinada enunciação, desdobrada em um contexto ao qual já não é possível retornar, acessar. Toda performance de menção a determinado contexto, em nome de algo, em defesa de uma perspectiva, é, desde já, uma fundação contextual tramada na menção às tradições, às formas de conhecimento, uma interpretação provisória, uma iteração (DERRIDA, 1991) daquilo a que se julga referir, mas que não se pode tangenciar, reprisar, represar na tentativa de conter o sentido do (con)texto curricular.

Por meio dessa visão, todo fazer, toda produção de conhecimento é uma prática contextual traidora, não sendo viável, portanto, a distinção entre um contexto formal e um da prática curricular, pois toda pretensão de significação só é possível se praticada contextualmente, em um "aqui e agora" (con)textual (DERRIDA, 1994). Pontuamos, nesse sentido, que toda tentativa de cálculo sobre o devir de um fazer curricular, de uma visão de prática de professores e alunos, do outro, bem como de qualquer identificação envolvida com o campo da educação, está em um movimento de falência perante o potencial generativo de toda significação.

Apoiar esta argumentação é conceber que não só o que se tem por contexto da prática não pode ser reduzido à performance diferencial de professores e alunos nas escolas, como, uma vez não restrito a práticas limitadas a instâncias físicas, o fazer conhecimento contextual, no contexto deste texto, como um exemplo, é toda 
possibilidade de produção de sentidos, de defesa de perspectivas que, certamente, já estâo em um trabalho de disseminação ante a alteridade. Trata-se de interpretar estas palavras, e todas as investidas em distintos outros espaços-tempos, como vivendo a ambivalência de poderem influenciar a produção de novos contextos e perecerem como verdades transcendentais. Para além das distinçóes e qualificaçóes, no registro das discussōes aqui propostas, só restam práticas (de significação) contextuais.

\section{Notas}

1. A terceira versão para o Ensino Médio ainda não havia sido divulgada.

\section{Referências}

ARROJO, R. (Org.). O signo desconstruido: implicaçóes para a tradução, a leitura e o ensino. Campinas: Pontes, 1992.

BENNINGTON, G.; DERRIDA, J. Jacques Derrida. Rio de Janeiro: Jorge Zahar, 1996.

BRASIL. Conselho Nacional de Educação (CNE). Parecer CNE/CEB no 7/2010, aprovado em 07/04/2010. Diretrizes Curriculares Nacionais Gerais para a Educaçáo Básica. Diário Oficial da União, Brasília, seção 1, p. 34, 15 dez. 2010a. Disponível em: <http://portal.mec.gov.br/index.php?option=com content\&view=article\&id=12992: dire trizespara-a-educacao-basica\&catid=323:orgaos-vinculados $>$. Acesso em: 4 abr. 2012.

. Conselho Nacional de Educação (CNE). Parecer no 15, de 1 de junho de 1998. Diretrizes Curriculares Nacionais para o Ensino Médio. Diário Oficial da União, Brasília, 1998.

. Conselho Nacional de Educação (CNE). Resolução CNE/CEB no 4/2010. Define Diretrizes Curriculares Nacionais Gerais para a Educação Básica. Diário Oficial da União, Brasília, seçáo 1, p. 824, 14 jul. 2010b. Disponível em: <http://portal.mec.gov. br/index.php?option=com content\&view=article\&id=12992:diretrizespara-a-educacaobasica\&catid=323:orgaos-vinculados $>$. Acesso em: 4 abr. 2012.

Ministério da Educação. Base Nacional Comum Curricular. 2. ed. abr. 2016. Disponível em: <http://historiadabncc.mec.gov.br/documentos/bncc-2versao.revista. pdf>. Acesso em: 7 ago. 2016.

- Ministério da Educação. Diretrizes Curriculares Nacionais para o Ensino Médio. Diário Oficial da União, Brasília, seção 1, p. 20, 31 jan. 2012.

CUNHA, E.; LOPES, A.C. Base Nacional Comum Curricular: regularidade na dispersão. Investigación Cualitativa, v. 2, p. 23-35, 2017. http://dx.doi.org/10.23935/2016/02023

DERRIDA, J. Dar la muerte. Barcelona: Paidós, 2006.

. Espectros de Marx. Rio de Janeiro: Relume-Dumará, 1994.

. Força de lei: o fundamento místico da autoridade. São Paulo: Martins Fontes, 2007. 
DERRIDA, J. Margens da filosofia. Campinas: Papirus, 1991.

. Posiçóes. Belo Horizonte: Autêntica, 2001.

. Uma certa possibilidade impossível de dizer o acontecimento. Cerrados, Brasília, v. 21, n. 33, p. 229-251, maio 2012. Disponível em: <www.periodicos.unb.br/index.php/ cerrados/article/download/8242/6240>. Acesso em: 12 out. 2017.

LACLAU, E. Democracy and the question of power. Constellations, v. 8, n. 1, p. 3-14, maio 2001. DOI: $10.1111 / 1467-8675.00212$ Desconstrucción, pragmatismo y hegemonía. In: MOUFFE, C. (Org.). Desconstrucción y pragmatismo. Buenos Aires: Paidós, 1998. p. $97-136$.

. New reflections on the revolution of our time. Londres: Verso, 1990.

LOPES, A.C. Democracia nas políticas de currículo. Cadernos de Pesquisa, v. 42, n. 147, p. 700-715, set.-dez. 2012. Disponível em: $\leq$ http://www.scielo.br/scielo.php?pid=S0100$15742012000300003 \&$ script $=$ sci_abstract\&tlng=es $>$. Acesso em: 15 out. 2013. http:// dx.doi.org/10.1590/S0100-15742012000300003

. Normatividade e intervenção política: em defesa de um investimento radical. In: LOPES, A.C.; MENDONÇA, D. de (Orgs.). A teoria do discurso de Ernesto Laclau: ensaios críticos e entrevistas. São Paulo: Annablume, 2015. p. 117-147.

Os parâmetros curriculares nacionais para o ensino médio e a submissão ao mundo produtivo: o caso do conceito de contextualização. Educação \& Sociedade, São Paulo, v. 23, n. 80, p. 386-400, 2002. Disponível em: <http://www.observatoriodoensinomedio.ufpr. br/wp-content/uploads/2014/02/OS-PCN-PARA-O-ENSINO-MEDIO.pdf $>$. Acesso em: 15 out. 2003.

LOPES, A.C.; MACEDO, E.F. Teorias de currículo. São Paulo: Cortez, 2011.

Recebido em 26 de agosto de 2017.

Aprovado em 04 de dezembro de 2017.

(C) 2018 Centro de Estudos Educação e Sociedade - CEDES Este é um artigo de acesso aberto distribuído nos termos de licença Creative Commons. 